\title{
Association among gestation length and health, production, and reproduction in Holstein cows and implications for their offspring
}

\author{
A. Vieira-Neto, ${ }^{*} \dagger$ K. N. Galvão, $\ddagger$ W. W. Thatcher, ${ }^{*} \dagger$ and J. E. P. Santos ${ }^{*} \dagger^{1}$ \\ *Department of Animal Sciences, \\ †D. H. Barron Reproductive and Perinatal Biology Research Program, and \\ fDepartment of Large Animal Clinical Sciences, University of Florida, Gainesville 32611
}

\begin{abstract}
Objectives were to evaluate associations among gestation length (GL) and performance in Holstein cows and their offspring. A total of 8,095 Holstein cows and 3,635 female offspring born alive on 2 farms using only artificial insemination (AI) were evaluated. Gestation length averaged $276 \pm 6 \mathrm{~d}$ in the 8,095 dams, and it was categorized as short (SGL; at least 1 SD below the population mean; mean $=266 \mathrm{~d}$, range 256 to $269 \mathrm{~d}$ ), average (AGL; population mean $\pm 1 \mathrm{SD} ;$ mean $=276 \mathrm{~d}$, range 270 to $282 \mathrm{~d}$ ), or long (LGL; at least $1 \mathrm{SD}$ above the population mean; mean $=285 \mathrm{~d}$, range 283 to 296 d). Responses evaluated in dams included incidence of diseases within $90 \mathrm{~d}$ in milk (DIM), pregnancy at first $\mathrm{AI}$ and by $300 \mathrm{DIM}$, and time to pregnancy. Milk yield and removal from the herd by culling or death were recorded for the first 300 DIM. Responses evaluated in female offspring born alive included removal from the herd and reproductive performance. Within primiparous cows, those with SGL had greater incidence of stillbirth, retained placenta, and metritis than primiparous with AGL or LGL; however, within multiparous cows, those with SGL or LGL had greater incidence of dystocia, stillbirth, retained placenta, and metritis than cows with AGL. Morbidity and rate of morbidity were greater for SGL and LGL than AGL. Rate of removal of dams from the herd was $38 \%$ faster for SGL than AGL. Milk production was greatest in AGL cows, but responses depended on parity. For primiparous cows, milk production was less in SGL and LGL than in $\mathrm{AGL}(\mathrm{AGL}=35.4, \mathrm{SGL}=34.6, \mathrm{LGL}=33.0 \pm 0.4$ $\mathrm{kg} / \mathrm{d}$ ), whereas for multiparous cows, production was less in SGL but greater in LGL than in AGL (AGL = 41.6, $\mathrm{SGL}=38.6, \mathrm{LGL}=42.4 \pm 0.3 \mathrm{~kg} / \mathrm{d}$ ). A smaller proportion of cows with SGL received at least one AI,
\end{abstract}

Received August 12, 2016.

Accepted November 26, 2016.

${ }^{1}$ Corresponding author: jepsantos@ufl.edu but pregnancy at first AI did not differ among groups. Rate of pregnancy was $11 \%$ slower for LGL multiparous than for AGL multiparous. By 300 DIM, pregnancy was greater in AGL than SGL. Pregnancy by 300 DIM in multiparous cows was also greater for AGL than LGL. Heifers from dams with GL that deviated from AGL had greater mortality postweaning (AGL $=3.2$ vs. $\mathrm{SGL}=6.5$ vs. $\mathrm{LGL}=5.4 \%$ ). The rate of removal from the herd was greater for SGL (adjusted hazard ratio $=1.78 ; 95 \%$ CI: 1.26 to 2.52 ) and LGL (adjusted hazard ratio $=2.00 ; 95 \%$ CI: 1.45 to 2.76 ) than for AGL heifers. Pregnancy at first AI was lowest for LGL and by $500 \mathrm{~d}$ of age a larger proportion of AGL heifers were pregnant than LGL (AGL $=82.3$ vs. $\mathrm{SGL}=79.2$ vs. LGL $=74.0 \%$ ). Cows with GL within $1 \mathrm{SD}$ of the population mean (270 to $282 \mathrm{~d}$ ) had improved health, production, and reproduction. Heifers from cows with GL within 1 SD of the population mean had improved health and reproduction. Gestation length affects performance of both dams and their offspring.

Key words: gestation length, health, offspring, reproduction

\section{INTRODUCTION}

Gestation length (GL) is the period between conception and parturition, and defining the expected GL is important from a management standpoint as the anticipated dates are used for drying off, movement between groups, and nutritional and health decisions. In some countries, GL is genetically manipulated in breeding programs to reduce the variability in calving patterns that facilitates seasonal production systems such as those used in New Zealand. Data from the sire proof program from the Livestock Improvement Corporation in New Zealand show that some bulls have a breeding value for GL of $-9 \mathrm{~d}$; that is, they can reduce GL by as much as $9 \mathrm{~d}$, which favors rebreeding of cows in seasonally breeding production systems, whereas others have a breeding value for gestation length of +5 
d (LIC, 2016). In the United States and many other countries, GL is not part of the breeding program, but it is considered for management decisions. In Holstein heifers and cows, GL averaged $( \pm \mathrm{SD}) 277.8 \pm 5.5$ and $279.4 \pm 5.7$, respectively (Norman et al., 2009).

Several factors have been identified to influence GL such as genetics, sex of the calf, singleton or twin pregnancy, age of dam, and season of the year. Dairy cows carrying male calves had GL $1.1 \mathrm{~d}$ longer than cows carrying female calves (Silva et al., 1992). Gestation with twins was shorter than that in cows carrying singletons (Echternkamp and Gregory, 1999). Days of gestation increased linearly as lactation number increased (McClintock et al., 2003). Cows calving during the warm season had GL 2.8 d shorter than cows calving during the cool season (DuBois and Williams, 1980). Genetics influence GL and some sires have predicted transmitting ability to either shorten or extend GL (Norman et al., 2009). Nogalski and Piwczyński (2012) found a linear relationship between GL and calf BW; the longer the GL, the greater the BW of the calf. Also, lack of proper alleviation of hyperthermia caused by heat stress in pregnant cows during the last 6 wk of gestation reduced GL by 3 to $4 \mathrm{~d}$ compared with cows provided evaporative cooling (Tao and Dahl, 2013). This likely explains the link between season of the year and length of gestation (Norman et al., 2009).

Several studies found large genetic variation in GL, and heritability has been estimated for genetic selection of this trait (DeFries et al., 1959; Jamrozik et al., 2005; Olson et al., 2009). Service sire heritability for GL is greater than that of the cow sire (Hansen et al., 2004): 33 to $36 \%$ for service sire and 7 to $12 \%$ for cow sire (Norman et al., 2009). Therefore, the use of semen with different PTA for GL may be an option to alter GL (LIC, 2016). According to Norman et al. (2009), sires can be used to either extend or reduce GL of cows; however, there is not enough information to suggest that either shortening or extending GL would provide advantages to the dam and the offspring in the Holstein breed under intensive production systems. Implementation of selection for GL has to consider possible effects on calving traits, survival of the calf, and subsequent performance of the dam and the offspring.

Norman et al. (2011) showed that intermediate GL, between 274 and $281 \mathrm{~d}$, optimized lifetime productivity, calving ease, incidence of stillbirth, and the interval from calving to first service in dams. Additionally, Jenkins et al. (2016) found that cows within the $5 \%$ shortest and the $5 \%$ longest GL of the study population produced less milk, fat, and protein, and had impaired offspring survival. Cows with GL $<275 \mathrm{~d}$ or $>281 \mathrm{~d}$ had increased incidence of dystocia and stillbirth compared with cows with GL between 275 and $281 \mathrm{~d}$ (Nogalski and Piwczyński, 2012). Furthermore, longer gestations were associated with increased incidence of metritis (Markusfeld, 1984).

Although several factors have been identified to influence GL in dairy cows, a comprehensive evaluation of the effect of GL on the dam's performance warrants further evaluation. Furthermore, the GL of the dam might have implications for the offspring beyond changes in the incidence of stillbirth. Better understanding of the potential implications of GL on health, reproduction, and productive performance of dairy cows, and the long-term effects on health, survival, and reproduction of the offspring might provide information that can be used to manage cows and calves selectively. Because GL can be manipulated genetically, the identification of an optimum GL might become a target for future use of sires that favor that particular duration of gestation to improve a dam's productivity and have long-term benefits to the offspring.

We hypothesized that an abnormal GL, either short or long, is associated with impairments in health, productive, and reproductive performance in Holstein cows that carries over to their offspring. Objectives of the present study were to evaluate the association between abnormal GL and health, productive, and reproductive performance in dairy cows, and survival and reproductive performance of their female offspring.

\section{MATERIALS AND METHODS}

\section{Farms and Cows}

This study followed a retrospective observational design. Data from 8,244 Holstein cows (3,335 primiparous and 4,909 multiparous) from 2 commercial dairies (farm $1, \mathrm{n}=1,886$; farm $2, \mathrm{n}=6,358$ ) located in central California that calved between January and December 2013 were collected for the study. A cow was included only once in the study and completed the study either at 300 DIM or when she was sold or died if those events occurred before 300 DIM.

Farm 1 was a dry-lot dairy that milked approximately 1,550 cows 4 times daily in the first 4 wk postpartum and then twice daily thereafter. Production was measured once a month, in 2 consecutive milkings, by the local DHIA laboratory (Hanford, CA). The rolling herd average for 2013 was $12,050 \mathrm{~kg}$ of $3.5 \%$ FCM. Prepartum nulliparous and parous cows and postpartum primiparous and multiparous cows were grouped separately throughout the entire dry and lactating periods, respectively. Dry lots had shades in the central area of the corrals and over the feed bunk. Approximately $6 \mathrm{~m}^{2}$ of shaded area was available per cow for lying. Shades were located north-south and dried manure was added 
twice weekly as bedding material under the shades. The bedding under the shaded area was raked once daily. Soaker lines with nozzles were placed above the stanchions in the feed lane, and the system was activated once the ambient temperature reached $22^{\circ} \mathrm{C}$ and nozzles sprayed water for approximately 1 min each 6 min. Lactating cows were fed the same TMR throughout the lactation, and it was formulated to meet or exceed the nutrient requirements of a $680-\mathrm{kg}$ cow consuming $27 \mathrm{~kg}$ of DM and producing $45 \mathrm{~kg}$ of milk with $3.70 \%$ fat and $3.30 \%$ true protein (NRC, 2001). Cows were fed twice daily and amounts offered were calculated daily for an estimated 2 to $3 \%$ orts. Cows were dried once weekly at $232 \pm 3$ d of gestation unless production was perceived to be very low by the herd manager, in which case the cow was dried earlier. Dry cows were moved into a drycow pen and fed a ration formulated for limited weight gain when the average DMI was $13 \mathrm{~kg} / \mathrm{d}$. Nulliparous and parous cows were moved into prepartum dry lots at $255 \pm 3 \mathrm{~d}$ of gestation and fed similar diets once daily, except that multiparous cows received a mixture containing acidogenic salts to minimize the risk of hypocalcemia postpartum. Cows calved either in their respective prepartum pens or in an adjacent maternity area.

Farm 2 milked approximately 5,400 cows thrice daily and the rolling herd average for 2013 was $13,100 \mathrm{~kg}$ of $3.5 \%$ FCM. Milk yield was recorded daily for individual cows using electronic milk meters (Perfection 3000, Boumatic, Madison, WI), and daily values were averaged into monthly means for statistical analysis. Cows were housed in sand-bedded freestalls in groups of 280 to 370 cows each. Dry cows were housed in freestalls, but cows and heifers in the last 3 wk of gestation were moved to prepartum dry lots and they calved either in the dry lots or in group maternity pens. Prepartum nulliparous and parous cows and postpartum primiparous and multiparous cows were grouped separately throughout the entire dry and lactating periods, respectively. Barns were equipped with fans in the central area above the stalls. Soaker lines with nozzles were located above the stanchions in the feed lane. The system was activated once ambient temperature reached $22^{\circ} \mathrm{C}$, and nozzles sprayed water for approximately 1 min each 6 min. All rations were fed as TMR. Lactating cows were fed an early lactation diet for the first 4 wk postpartum, moved to a diet labeled "high cow ration" fed to cows between 4 wk and approximately 200 to 250 DIM, and then to a diet labeled "low cow ration" fed to cows after 250 DIM. Change of diets from the high to the low cow ration groups was based on milk yield of the cow and space needs in the barns at the discretion of the herd manager. Dietary ingredients were the same in all rations, but proportions of forage, concentrates, and protein supplements were altered to accommodate the nutrient needs of each group of cows according to production level and group DMI. Diets were formulated for expected DMI of 20, 28, and 25 $\mathrm{kg} / \mathrm{d}$ for the early lactation, high group, and low group rations. Cows were fed once daily and amounts offered were calculated daily for an estimated 2 to $3 \%$ orts. Cows were dried once weekly, at $232 \pm 3 \mathrm{~d}$ of gestation unless production was perceived to be very low by the herd manager, in which case, the cow was dried earlier. Dry cows were moved into a dry-cow pen and fed a ration formulated for limited weight gain when the average DMI was $13 \mathrm{~kg} / \mathrm{d}$. Prepartum nulliparous and parous cows were moved into dry lots at $255 \pm 3$ $\mathrm{d}$ of gestation and fed similar diets once daily, except that multiparous cows received a mixture containing acidogenic salts to minimize the risk of hypocalcemia postpartum. In both farms, cows received treatments with bST (Posilac, sometribove zinc suspension for injection, Elanco Animal Health, Greenfield, IN) every 14 d starting at $70 \pm 3 \mathrm{DIM}$, and treatments were stopped $14 \mathrm{~d}$ before the expected dry off date.

\section{Management and Feeding of Calves and Heifers}

On both farms, newborn female calves were identified with numbered eartags and received $4 \mathrm{~L}$ of colostrum by esophageal tube feeding within $4 \mathrm{~h}$ of birth and another $2 \mathrm{~L}$ of colostrum in the next feeding. Female calves on both farms were transported twice daily to the same calf-raising facility in farm 2, where they remained until $63 \mathrm{~d}$ of age. Calves were housed in individual calf hutches and had access to water and starter grain from birth until they left the hutches at $63 \mathrm{~d}$ of age.

Calves were fed pasteurized hospital milk for the first 3 to 4 wk of life, depending on availability, after which they were fed milk replacer at $13 \%$ DM. Calves were fed 3 times daily with $2 \mathrm{~L}$ of milk per feeding for the first $4 \mathrm{wk}$ of life, followed by twice daily until the end of wk 7 and once daily in wk 8 , after which they were weaned from milk. Calves remained in the individual hutches until approximately $63 \mathrm{~d}$ of age, when they returned to the respective farm of origin and were housed in group pens according to age. On both farms, heifers were fed 2 diets, one before reaching the breeding group and another during breeding and pregnancy. Diets were formulated according to NRC (2001) to achieve daily weight gain of 850 to $950 \mathrm{~g} / \mathrm{d}$.

\section{Data Collection}

Dam Data. Data regarding health, production, and reproduction were collected from the dairy management software Dairy Comp 305 (Valley Agricultural 
Software, Tulare, CA). Calving information such as dystocia, stillbirth, twin, sex of the calf, and season of calving were recorded. The hot season was defined as the period between June 1 and October 15, and the rest of the year was classified as the cool season. This classification was based on elevated ambient temperature observed in the location of the 2 farms in 2013 based on the local weather station (Hanford, CA). Cows were diagnosed as having retained fetal membranes (RFM) if the placenta was not expelled within $24 \mathrm{~h}$ of calving. Cows were evaluated daily for diagnosis of diseases for the first 3 to 4 wk postpartum. Diseases were recorded for the first 90 DIM and included metritis (watery, reddish or brownish vaginal discharge with foul smell), pneumonia (fever, increased respiratory frequency, and sounds at auscultation), lameness based on routine therapeutic hoof trimming, displaced abomasum (auscultation followed by confirmation during corrective surgery), and mastitis (abnormal milk and inflammation of the gland). Removal from the herd, either by culling or death, was recorded up to 300 DIM. In farm 1, milk yield was recorded once a month during 2 consecutive milkings by the local DHIA laboratory, whereas in farm 2, milk yield was measured daily and averaged for each month postpartum.

Both farms followed the same reproductive management protocols. Cows had the estrous cycle synchronized with 2 injections of $25 \mathrm{mg}$ of $\mathrm{PGF}_{2 \alpha}$ (Lutalyse Sterile Solution, $5 \mathrm{mg} / \mathrm{mL}$ dinoprost as tromethamine salt, Zoetis, Florham Park, NJ) administered $14 \mathrm{~d}$ apart at 37 and $51 \pm 3$ DIM. Cows were observed daily in the morning for signs of estrus based on removal of tail chalk, and the voluntary waiting period was 51 DIM. Cows not inseminated by $62 \pm 3$ DIM were enrolled in the Ovsynch-56 timed AI protocol (Brusveen et al., 2008) such that every cow on both farms received the first postpartum AI no later than 75 DIM. Cows that returned to estrus after any AI were inseminated in the same morning and considered to be nonpregnant to the previous breeding. Pregnancy was diagnosed by ultrasound at $32 \pm 3 \mathrm{~d}$ after $\mathrm{AI}$, and pregnant cows were reconfirmed 4 wk later, at $60 \pm 3 \mathrm{~d}$ of gestation. Visualization of an amniotic vesicle with an embryo was the criterion used to determine pregnancy. Nonpregnant cows were re-enrolled in the Ovsynch-56 protocol for reinsemination. Pregnancy loss between 32 and 60 $\mathrm{d}$ of gestation was evaluated for the first postpartum AI. Pregnancy per AI (P/AI) was calculated for the first AI and for all AI by dividing the number of cows diagnosed pregnant by the number that received AI. For the purpose of this study, a cow was considered pregnant when a positive diagnosis was determined on d 60 after insemination. Reproductive data were collected until a cow was confirmed pregnant, sold, died, or up to 300 DIM, whichever occurred first. Nonpregnant cows by 300 DIM were censored for analysis of time to pregnancy.

Heifer Data. A total of 3,635 heifers were born alive and moved to individual hutches, 2,887 from dams with average GL, 341 born from dams with short GL, and 407 born from dams with long GL (as defined in the next section). Heifers born alive but from female-male twins were not included in the analyses because those females were likely to be freemartins and they were sold with the male calves. Live-born females were followed for the first $300 \mathrm{~d}$ of life for survival. Individual calf disease incidence was not recorded properly, so information was not collected for analyses. Survival during the preweaning period and the first $300 \mathrm{~d}$ of life were analyzed.

Heifers on both farms were moved to the breeding group based on age and hip height. Starting at 12 mo of age, heifers with hip height $\geq 130 \mathrm{~cm}$ were moved to the breeding groups; otherwise, all heifers were moved at 13 mo of age. Weekly cohorts of heifers were moved to dry lots equipped with stanchions with self-lockups for daily activities. Heifers had tailheads painted daily with chalk (All Weather Paintstik, LA-CO Industries Inc., Elk Grove Village, IL), and removal of the chalk was interpreted as an indication of estrus. Heifers were evaluated daily in the morning immediately after feeding, and any heifer showing signs indicative of estrus such as accepting mounts or with rubbed tailheads were inseminated on the same morning. Heifers that did not show signs of estrus within $14 \mathrm{~d}$ of moving to the breeding pen had ovaries scanned by transrectal ultrasonography, and those with visible corpus luteum received a dose of $25 \mathrm{mg}$ of $\mathrm{PGF}_{2 \alpha}$ that was repeated every $14 \mathrm{~d}$ until insemination.

Pregnancy was evaluated once every 2 wk when heifers were 35 to $48 \mathrm{~d}$ after AI. Pregnancy diagnosis was performed by transrectal ultrasonography as described previously. Heifers that returned to estrus after any AI and before a pregnancy diagnosis were considered nonpregnant. Nonpregnant heifers on the day of pregnancy diagnosis received a dose of $\mathrm{PGF}_{2 \alpha}$ to synchronize the return to estrus. Pregnancy per AI was calculated by dividing the number of heifers diagnosed pregnant by the number of heifers that received AI. Reproductive performance was evaluated until $500 \mathrm{~d}$ of age. For interval to pregnancy, nonpregnant heifers were censored either when last observed in the farm because of being sold or dead, or at $500 \mathrm{~d}$ of age.

\section{Gestation Length Category}

Gestation length was determined as the interval between the day of AI that resulted in pregnancy and 
the day of calving. Descriptive statistics were used to characterize the distribution of GL resulting in a mean $( \pm \mathrm{SD})$ of $276 \pm 7 \mathrm{~d}$ in the original population of 8,244 cows. Cows with GL shorter or longer than 3 SD from the mean were removed and considered outliers. This process resulted in 149 of the initial 8,244 enrolled cows being removed from the study. Of the 149 cows removed because of extreme GL, 91 had gestations $<256 \mathrm{~d}$ (mean of $244.4 \mathrm{~d}$, range: 194 to $255 \mathrm{~d}$ ), and 58 had gestations $>296 \mathrm{~d}$ (mean of $305.7 \mathrm{~d}$, range: 297 to $340 \mathrm{~d}$ ). These extreme GL values likely occurred either because of late-term abortions that were recorded as typical calf birth or because of incorrect identification of the date of AI that resulted in pregnancy. Therefore, 8,095 cows remained for data analyses and the range of GL was 256 to $296 \mathrm{~d}$.

Subsequent descriptive statistics were performed for GL from the 8,095 cows remaining in the study, which resulted in a mean and SD of $276 \pm 6$ d. Three categories of GL were created. Cows with GL within \pm $1 \mathrm{SD}$ of the study population mean were classified as average GL (AGL, $\mathrm{n}=6,181$, mean $=276$, range 270 to 282 d). Cows with GL shorter than 1 SD from the study population mean were classified as having short GL (SGL, $\mathrm{n}=762$, mean $=266$, range 256 to $269 \mathrm{~d}$ ). Cows with GL longer than 1 SD from the study population mean were classified as having long GL (LGL, n $=1,152$, mean $=285$, range 283 to $296 \mathrm{~d}$ ). Therefore, AGL, SGL, and LGL represented 76.4, 9.4, and $14.2 \%$ of the study population, respectively.

\section{Statistical Analyses}

Dam Data. Continuous data such as milk yield or DIM at first AI were analyzed by ANOVA using the MIXED procedure of SAS (version 9.4; SAS/STAT, SAS Institute Inc., Cary, NC). Binary data such as incidence of diseases, morbidity, $\mathrm{P} / \mathrm{AI}$, and pregnancy loss were analyzed by logistic regression using the GLIMMIX procedure of SAS. Time to an event, such as days postpartum to pregnancy or leaving the herd, was analyzed by the Cox's proportional hazard regression model with the PHREG procedure of SAS. All models included the fixed effects of GL category (AGL vs. SGL vs. LGL), parity (primiparous vs. multiparous), season of calving (cool vs. hot), farm (1 vs. 2), sex of calf (male, female, twin), and interactions between GL category and farm, GL category and parity, and GL category and season. Nonsignificant $(P>0.10)$ interactions were dropped from the final models. The random effect of maternal grandsire was included in the models to adjust for differences in genetic merit. Pairwise comparisons among groups were adjusted according to the method of Tukey. Additional statistical analyses of incidence of diseases, death, and culling were performed, excluding cows that had twin pregnancy. The statistical models were the same, except that calf sex included only singleton female and singleton male.

Heifer Data. Continuous data such as age at first AI were analyzed by ANOVA using the MIXED procedure of SAS. Binary data such as incidence of death or P/AI were analyzed by logistic regression using the GLIMMIX procedure of SAS. Time to an event such as days to leaving the herd or pregnancy was analyzed by the Cox's proportional hazard regression model with the PHREG procedure of SAS. All models included the fixed effects of gestation length category (AGL vs. SGL vs. LGL), season of calving (cool vs. hot), twin (0 vs. 1), farm (1 vs. 2), parity of the dam (primiparous vs. multiparous), and interactions between GL category and season, and GL category and farm. Nonsignificant $(P>0.10)$ interactions were dropped from the final models. The random effect of maternal sire was included in the models to adjust for differences in genetic merit. Pairwise comparisons among groups were adjusted according to the method of Tukey.

Significance was declared when $P \leq 0.05$ and a tendency to differ at $0.05<P \leq 0.10$.

\section{RESULTS}

Factors associated with GL were parity of the dam, sex of the calf, singleton or twin gestation, and season of calving. Nulliparous cows had shorter $(P<0.01) \mathrm{GL}$ than parous cows (nulliparous $=274.1 \pm 0.2$ vs. parous $=276.8 \pm 0.2 \mathrm{~d}$ ). Cows carrying female calves had 1.3 d shorter $(P<0.01)$ GL than cows carrying male calves (275.4 \pm 0.1 and $276.7 \pm 0.1 \mathrm{~d}$, respectively). Moreover, for cows carrying twins, those carrying female-female or female-male had shorter $(P<0.05)$ GL that cows carrying male-male [female-female $=274.3 \pm 0.7(\mathrm{n}=96)$, female-male $=273.6 \pm 0.5(\mathrm{n}=175)$, and male-male $=277.3 \pm 0.6 \mathrm{~d}(\mathrm{n}=87)]$. Cows calving during the hot season had $1.5 \mathrm{~d}$ shorter $(P<0.01)$ GL than cows calving during the cool season (hot $=274.7 \pm 0.2$ vs. $\mathrm{cool}=276.2 \pm 0.2 \mathrm{~d})$.

\section{Health Performance of All Dams}

The incidence of dystocia did not differ among GL categories within primiparous cows; however, within multiparous cows, dystocia was greater $(P<0.05)$ in cows having SGL than in those with LGL or AGL, and those with LGL had greater $(P<0.05)$ incidence of dystocia than cows with AGL (Table 1). The incidence of stillbirth was greater $(P<0.05)$ in cows having SGL than in those with AGL or LGL regardless of parity, although the increase in stillbirth observed with SGL 
Table 1. Associations between gestation length category (GLC) ${ }^{1}$ and incidence of diseases, culling, or mortality in all Holstein cows according to parity

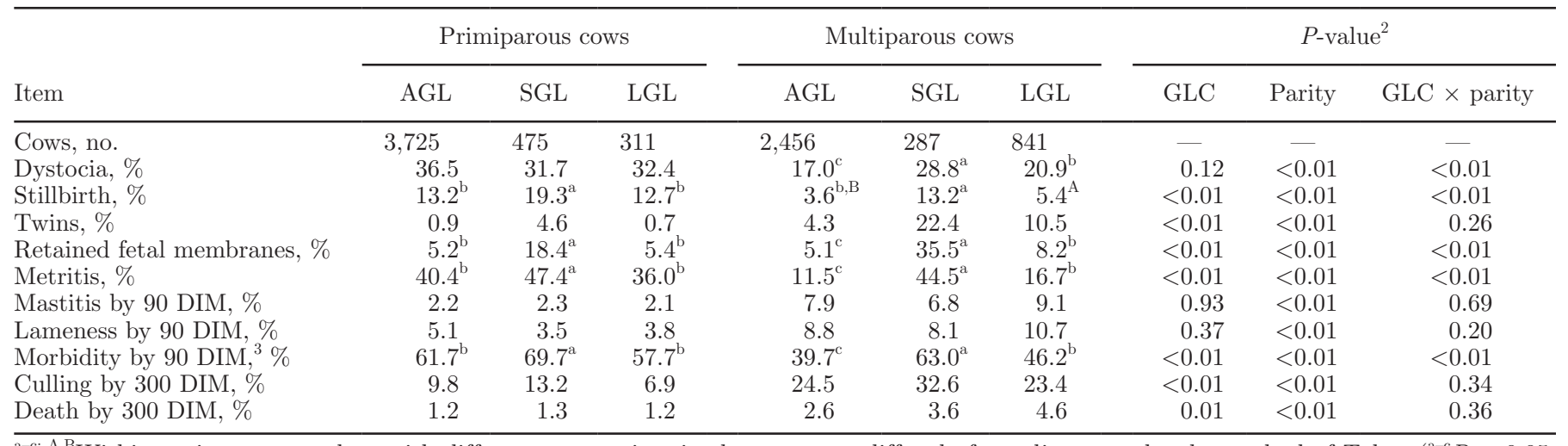

${ }^{\mathrm{a}-\mathrm{c} ; \mathrm{A}, \mathrm{B}}$ Within parity group, values with different superscripts in the same row differed after adjustment by the method of Tukey $\left({ }^{\mathrm{a}-\mathrm{c}} P<0.05\right.$; $\left.{ }^{\mathrm{A}, \mathrm{B}} 0.05<P \leq 0.10\right)$.

${ }^{1}$ Gestation length was categorized as average (AGL; population mean $\pm 1 \mathrm{SD}$; mean $=276 \mathrm{~d}$, range 270 to $282 \mathrm{~d}$ ), short (SGL; at least 1 SD below the population mean; mean $=266 \mathrm{~d}$, range 256 to $269 \mathrm{~d}$ ), or long (LGL; $>1$ SD above the population mean; mean $=285 \mathrm{~d}$, range 283 to $296 \mathrm{~d})$.

${ }^{2} \mathrm{GLC}=$ effect of gestation length category (AGL vs. SGL vs. LGL); Parity $=$ effect of parity group (primiparous vs. multiparous); GLC $\times$ parity = interaction between GLC and parity.

${ }^{3}$ Morbidity included at least one the following conditions: retained fetal membranes, metritis, mastitis, lameness, and other diseases such as milk fever, displaced abomasum, pneumonia, and bloat.

was greater in multiparous than in primiparous cows. Cows with LGL had greater $(P<0.05)$ incidence of stillbirth within primiparous cows and tended $(P=$ $0.08)$ to have a greater incidence of stillbirth within multiparous than those with AGL. Incidence of twin gestation was greater $(P<0.001)$ in cows with SGL than in those with AGL or LGL in both primiparous and multiparous cows. Multiparous cows had greater $(P<0.001)$ incidence of twins than primiparous. Incidence of RFM was greater $(P<0.001)$ in SGL than in cows with AGL or LGL, but an interaction $(P<$ 0.001 ) between GL and parity was observed because the increase was more pronounced in multiparous than in primiparous cows. Both primiparous and multiparous cows had greater $(P<0.01)$ incidence of metritis in SGL compared with AGL or LGL; however, a difference between AGL and LGL was only observed in multiparous cows. Incidence of mastitis was not associated with GL, and multiparous cows had greater $(P$ $<0.01$ ) incidence of mastitis than primiparous cows. Incidence of lameness was not associated with GL, but multiparous cows had greater $(P<0.01)$ incidence of lameness compared with primiparous cows. Because of the differences in incidence of individual diseases, morbidity by 90 DIM was greater $(P<0.01)$ in cows with SGL compared with AGL or LGL regardless of parity; however, the increment in morbidity observed in cows with SGL was greater for multiparous than primiparous cows. In addition, multiparous cows with LGL had greater $(P=0.02)$ incidence of morbidity than multiparous cows with AGL, and the same response was not observed within primiparous cows. Figure 1 depicts the survival curves for days postpartum at the first diagnosis of disease up to 90 DIM for primiparous and multiparous cows according to GL category. It is clear that most cows were first diagnosed with disease within 2 to 3 wk postpartum. Primiparous and multiparous cows with SGL had greater $(P<0.01)$ rate of morbidity than cows with AGL (Table 2). Nevertheless, LGL resulted in a greater rate of morbidity compared with AGL only for multiparous cows; no difference was observed between the 2 groups in primiparous cows. In addition, the rate of morbidity was greater $(P<0.01)$ for cows calving during the hot than the cool season, and for cows calving twins than those calving singleton either male or female. No interactions were observed between GL category and season or calf sex.

Culling in the first 300 DIM was greater $(P<0.01)$ in SGL than in AGL or LGL regardless of parity (Table 1). No difference was observed between AGL and LGL. Culling was greater $(P<0.01)$ in multiparous than primiparous cows. Death by 300 DIM was greater $(P$ $<0.01)$ in LGL than in AGL, but no difference was observed between SGL and AGL or between SGL and LGL. Figure 2 depicts the survival curves for time to removal from herd either by culling or death by 300 DIM according to GL category. Cows with SGL were removed from the herd at a greater $(P<0.01)$ rate than cows with AGL (Table 3); LGL and AGL did not differ. In addition, multiparous cows were removed from the herd almost 2.6 -fold faster $(P<0.01)$ than primiparous cows; cows calving in the cool season were removed 
at a greater $(P<0.01)$ rate than those calving in the hot season; and those calving twins were removed at a greater $(P<0.01)$ rate than those calving a singleton male or female calf.

\section{Health Performance of Dams Calving Singletons}

Of the 8,095 Holstein cows in the study, 7,737 calving singletons remained in the analyses of health data for dams calving a single calf $(\mathrm{AGL}=5,998 ; \mathrm{SGL}=675$; LGL $=1,064)$. The other 358 were excluded because they delivered twin calves.

Health data of dams calving singletons were similar to those of all cows. An interaction $(P<0.01)$ between GL category and parity was observed for incidence of dystocia, because within multiparous cows, those with SGL had greater $(P<0.05)$ incidence of dystocia than
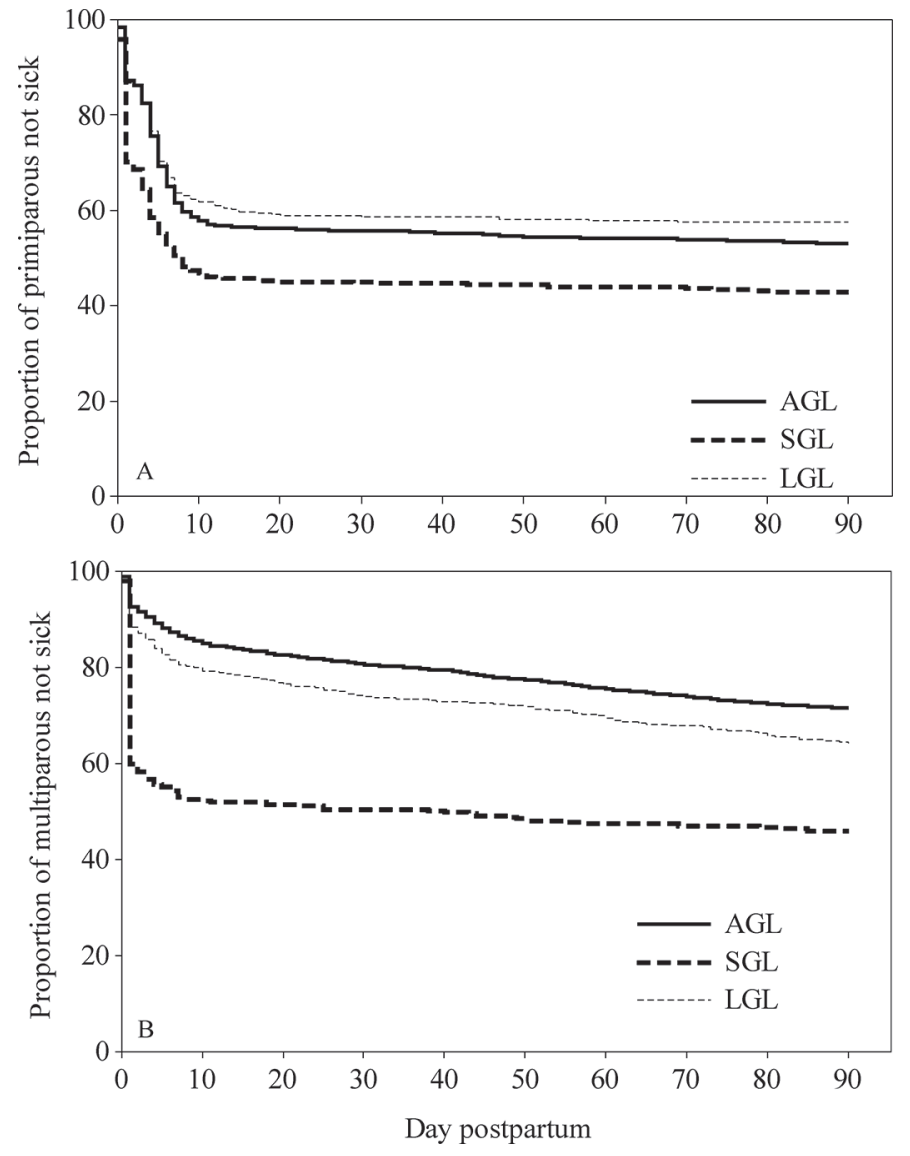

Figure 1. Survival curves for time to diagnosis of disease up to 90 DIM in primiparous (A) and multiparous Holstein cows (B) according to gestation length category. Gestation length was categorized as average (AGL; population mean $\pm 1 \mathrm{SD}$; mean $=276 \mathrm{~d}$, range 270 to $282 \mathrm{~d} ; \mathrm{n}=6,181$ ), short (SGL; at least $1 \mathrm{SD}$ below the population mean; mean $=266 \mathrm{~d}$, range 256 to $269 \mathrm{~d} ; \mathrm{n}=762$ ), and long (LGL $>1 \mathrm{SD}$ above the population mean; mean $=285 \mathrm{~d}$, range 283 to 296 $\mathrm{d} ; \mathrm{n}=1,152)$.
Table 2. Cox's regression model for time to diagnosis of disease up to 90 DIM in Holstein cows

\begin{tabular}{|c|c|c|c|}
\hline Item (cows) & $\mathrm{AHR}^{1}$ & $95 \% \mathrm{CI}$ & $P$-value \\
\hline Gestation length $^{2} \times$ parity & & & $<0.01$ \\
\hline \multicolumn{4}{|l|}{ Primiparous } \\
\hline AGL $(2,456)$ & Referent & - & - \\
\hline SGL (475) & 1.34 & $1.17-1.53$ & $<0.01$ \\
\hline LGL (311) & 0.89 & $0.73-1.07$ & 0.21 \\
\hline \multicolumn{4}{|l|}{ Multiparous } \\
\hline AGL $(3,725)$ & Referent & - & - \\
\hline SGL (287) & 2.16 & $1.80-2.58$ & $<0.01$ \\
\hline LGL (841) & 1.15 & $1.01-1.32$ & 0.03 \\
\hline \multicolumn{4}{|l|}{ Season of calving } \\
\hline Hot $(3,408)$ & Referent & - & — \\
\hline Cool $(4,687)$ & 0.82 & $0.77-0.88$ & $<0.01$ \\
\hline Sex of calf & & & $<0.01$ \\
\hline Twin (359) & Referent & - & - \\
\hline Male $(3,612)$ & 0.27 & $0.24-0.31$ & $<0.01$ \\
\hline Female $(4,124)$ & 0.20 & $0.18-0.24$ & $<0.01$ \\
\hline \multicolumn{4}{|l|}{ Farm } \\
\hline $1(1,841)$ & Referent & - & - \\
\hline $2(6,254)$ & 0.93 & $0.85-1.01$ & 0.07 \\
\hline
\end{tabular}

${ }^{1}$ Adjusted hazard ratio of the hazard rates from the Cox's regression between a level of the predictor compared with the reference level for the same predictor. A value $<1$ indicates a reduced rate of the event, whereas a value $>1$ indicates an increase in the rate of the event.

${ }^{2}$ Gestation length was categorized as average (AGL; population mean $\pm 1 \mathrm{SD}$; mean $=276 \mathrm{~d}$, range 270 to $282 \mathrm{~d}$ ), short (SGL; at least $1 \mathrm{SD}$ below the population mean; mean $=266 \mathrm{~d}$, range 256 to $269 \mathrm{~d}$ ), and long (LGL; $>1$ SD above the population mean; mean $=285 \mathrm{~d}$, range 283 to 296 d).

cows with AGL or LGL (Table 4). Also, dams with LGL had greater $(P<0.05)$ incidence of dystocia than those with AGL. Cows with SGL had greater $(P<$ 0.01) incidence of stillbirth than those with AGL or LGL, but the increase was greater within multiparous

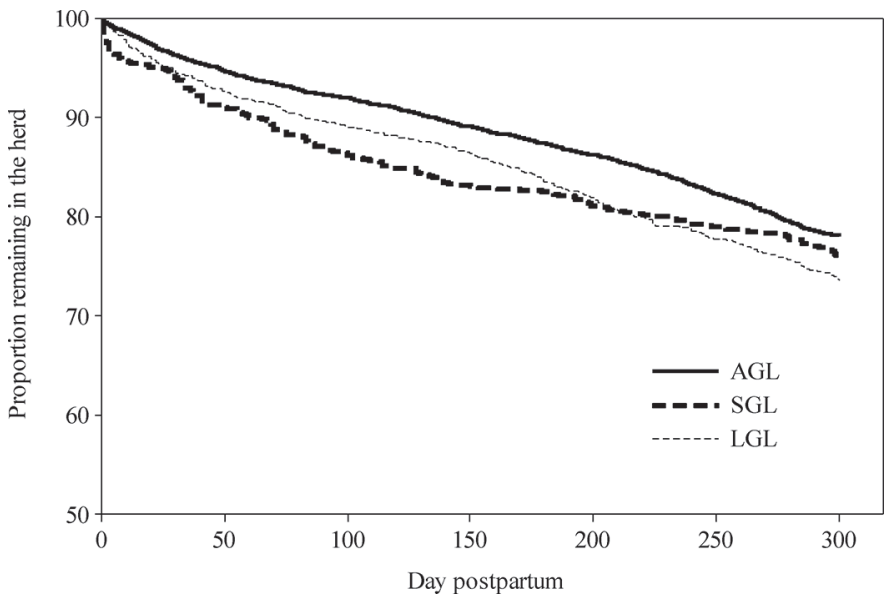

Figure 2. Survival curves for time to leaving the herd either by culling or death up to 300 DIM in Holstein cows according to gestation length category. Gestation length was categorized as average (AGL; population mean $\pm 1 \mathrm{SD}$; mean $=276 \mathrm{~d}$, range 270 to $282 \mathrm{~d}$; $\mathrm{n}=$ 6,181 ), short (SGL; at least 1 SD below the population mean; mean $=266 \mathrm{~d}$, range 256 to $269 \mathrm{~d} ; \mathrm{n}=762$ ), and long (LGL; $>1$ SD above the population mean; mean $=285 \mathrm{~d}$, range 283 to $296 \mathrm{~d}$; $\mathrm{n}=1,152)$. 
Table 3. Cox's regression model for time to removal from the herd up to 300 DIM in Holstein cows

\begin{tabular}{lccc}
\hline Item (no. of cows) & AHR $^{1}$ & $95 \%$ CI & $P$-value \\
\hline Gestation length & & & $<0.01$ \\
AGL (6,181) & Referent & - & - \\
SGL (762) & 1.38 & $1.17-1.62$ & $<0.01$ \\
LGL (1,152) & 1.09 & $0.96-1.24$ & 0.17 \\
Parity & & & \\
Primiparous (3,242) & Referent & - & - \\
Multiparous (4,853) & 2.56 & $2.29-2.86$ & $<0.01$ \\
Season of calving & & & \\
Hot (3,408) & Referent & - & - \\
Cool (4,687) & 1.16 & $1.05-1.27$ & $<0.01$ \\
Sex of calf & & & $<0.01$ \\
Twin (359) & Referent & - & - \\
Male (3,612) & 0.77 & $0.63-0.93$ & $<0.01$ \\
Female (4,124) & 0.71 & $0.59-0.87$ & $<0.01$ \\
Farm & & & \\
1 (1,841) & Referent & - & - \\
$2(6,254)$ & 1.18 & $1.05-1.32$ & $<0.01$ \\
\hline
\end{tabular}

${ }^{1}$ Adjusted hazard ratio of the hazard rates from the Cox's regression between a level of the predictor compared with the reference level for the same predictor. A value $<1$ indicates a reduced rate of the event, whereas a value $>1$ indicates an increase in the rate of the event.

${ }^{2}$ Gestation length was categorized as average (AGL; population mean $\pm 1 \mathrm{SD}$; mean $=276 \mathrm{~d}$, range 270 to $282 \mathrm{~d}$ ), short (SGL; at least $1 \mathrm{SD}$ below the population mean; mean $=266 \mathrm{~d}$, range 256 to $269 \mathrm{~d}$ ), and long (LGL; $>1$ SD above the population mean; mean $=285 \mathrm{~d}$, range 283 to 296 d).

than within primiparous cows. Also, within multiparous cows, those with LGL had greater $(P<0.05)$ incidence of stillbirth calvings than cows with AGL. The incidence of RFM in cows with SGL was 3-fold greater $(P<0.01)$ in primiparous and 7 -fold greater in multiparous compared with AGL and LGL cows. No statistical difference was observed between AGL and LGL for the incidence of RFM. Similar to RFM, the incidence of metritis was greater $(P<0.01)$ in cows with SGL than in those with AGL or LGL, but the increment was larger $(P<0.01)$ in multiparous than in primiparous cows. The incidence of mastitis did not differ with GL category. A tendency for an interaction $(P=0.10)$ between GL category and parity was observed for lameness because multiparous cows with LGL had greater $(P=0.03)$ incidence than multiparous cows with AGL, a difference that was not observed within primiparous cows. The differences observed for individual diseases in dams calving singletons resulted in greater $(P<0.01)$ morbidity for SGL than for AGL or LGL cows, and the increase in morbidity was more exacerbated in multiparous than in primiparous cows. Furthermore, within multiparous cows, those with LGL had greater morbidity compared with AGL cows, a response that was not observed in primiparous cows. The greater morbidity in SGL cows resulted in greater $(P<0.01)$ risk of culling compared with AGL or LGL cows. On the other hand, no statistical differences were observed in death of cows calving singletons according to GL category.

\section{Production Performance of All Dams}

Cows with AGL produced more $(P<0.01)$ milk than cows with either SGL or LGL (Table 5). Nevertheless, important interactions between GL category and parity and between GL category and farm were observed.

Table 4. Associations between gestation length category $(\mathrm{GLC})^{1}$ and incidence of diseases, culling, or mortality in Holstein cows calving singletons according to parity

\begin{tabular}{|c|c|c|c|c|c|c|c|c|c|}
\hline Item & \multicolumn{3}{|c|}{ Primiparous cows } & \multicolumn{3}{|c|}{ Multiparous cows } & \multicolumn{3}{|c|}{$P$-value ${ }^{2}$} \\
\hline Cows, no. & 2,433 & 452 & 309 & 3,565 & 223 & 755 & - & - & - \\
\hline Stillbirth, \% & $7.3^{\mathrm{b}}$ & $14.4^{\mathrm{a}}$ & $7.1^{\mathrm{b}}$ & $1.7^{\mathrm{c}}$ & $10.0^{\mathrm{a}}$ & $2.9^{\mathrm{b}}$ & $<0.01$ & $<0.01$ & $<0.01$ \\
\hline Retained fetal membranes, $\%$ & $4.5^{\mathrm{b}}$ & $15.7^{\mathrm{a}}$ & $4.5^{\mathrm{b}}$ & $3.7^{\mathrm{b}}$ & $28.6^{\mathrm{a}}$ & $4.6^{\mathrm{b}}$ & $<0.01$ & 0.20 & $<0.01$ \\
\hline Metritis, \% & $39.2^{\mathrm{b}}$ & $45.0^{\mathrm{a}}$ & $33.9^{\mathrm{b}}$ & $9.1^{\mathrm{b}}$ & $36.9^{\mathrm{a}}$ & $10.9^{\mathrm{b}}$ & $<0.01$ & $<0.01$ & $<0.01$ \\
\hline Culling by 300 DIM, $\%$ & 9.6 & 15.3 & 6.2 & 24.2 & 35.2 & 21.9 & $<0.01$ & $<0.01$ & 0.32 \\
\hline Death by 300 DIM. \% & 1.2 & 1.3 & 1.2 & 2.5 & 2.5 & 3.9 & 0.11 & $<0.01$ & 0.51 \\
\hline
\end{tabular}

${ }^{\mathrm{a}-\mathrm{c}}$ Within parity group, values with different superscripts in the same row differed after adjustment by the method of Tukey $(P<0.05)$.

${ }^{1}$ Gestation length was categorized as average (AGL; population mean $\pm 1 \mathrm{SD}$; mean $=276 \mathrm{~d}$, range 270 to $282 \mathrm{~d}$ ), short (SGL; at least 1 SD below the population mean; mean $=266 \mathrm{~d}$, range 256 to $269 \mathrm{~d}$ ), or long (LGL; >1 SD above the population mean; mean $=285 \mathrm{~d}$, range 283 to $296 \mathrm{~d}$ ).

${ }^{2} \mathrm{GLC}=$ effect of gestation length category (AGL vs. SGL vs. LGL); Parity $=$ effect of parity group (primiparous vs. multiparous); GLC $\times$ parity = interaction between GLC and parity.

${ }^{3}$ Morbidity includes at least one the following conditions: retained fetal membranes, metritis, mastitis, lameness, and other diseases such as milk fever, displaced abomasum, pneumonia, and bloat. 
Within primiparous cows, those with LGL produced 2.4 $\mathrm{kg} / \mathrm{d}$ less milk $(P<0.01)$ than primiparous cows with AGL, whereas those with SGL produced $0.8 \mathrm{~kg} / \mathrm{d}$ less milk $(P<0.01)$ than primiparous cows with AGL. On the other hand, within multiparous cows, production of milk was lower $(P<0.01)$ in cows with SGL than those with AGL, but cows with LGL produced $0.8 \mathrm{~kg} / \mathrm{d}$ more milk $(P<0.01)$ than multiparous cows with AGL. In farm 1, SGL produced less $(P<0.01)$ milk than AGL, but no difference was observed between AGL and LGL, whereas in farm 2, both SGL and LGL produced less $(P<0.01)$ milk than cows with AGL. Cows calving in the hot season produced $0.5 \mathrm{~kg} / \mathrm{d}$ more milk than those calving in the cool season. Sex of calf did not affect daily milk yield in the first 300 DIM.

\section{Reproductive Performance of All Dams}

The proportion of cows receiving at least one AI was less $(P<0.01)$ in SGL than in AGL cows, regardless of parity (Table 6 ). Within primiparous, LGL did not differ from AGL but, within multiparous, a larger $(P$ $=0.02)$ proportion of AGL cows received at least one AI compared with LGL cows. Despite the difference in percentage of cows inseminated, the DIM at first AI did not differ with GL category. Pregnancy at first AI was not affected by GL category on either d 32 or d 60 after insemination. Gestation length was not associated with pregnancy loss between 32 and $60 \mathrm{~d}$ of gestation following the first AI. By 300 DIM, a larger $(P<0.01)$ proportion of AGL than SGL became pregnant in both primiparous and multiparous cows; however, a tendency for interaction $(P=0.06)$ was observed between GL category and parity because, within primiparous, no difference was observed between AGL and LGL but a larger $(P<0.05)$ proportion of AGL multiparous than LGL multiparous became pregnant by 300 DIM. Similarly, an interaction $(P=0.02)$ between GL category and parity was observed for rate of pregnancy. Within primiparous cows, GL category did not influence the rate of pregnancy; however, within multiparous cows, those with AGL became pregnant faster than cows with LGL, resulting in a reduction in median days to pregnancy of 12 d (Table 7; Figure 3). No difference was observed between AGL and SGL or between SGL and LGL for rate of pregnancy. Primiparous cows became pregnant faster $(P<0.01)$ than multiparous cows, which resulted in 10 fewer median days to pregnancy (Table 7). Cows calving in the hot season became pregnant $4 \mathrm{~d}$ earlier $(P<0.01)$ than cows calving in the cool season, and those calving female calves tended $(P$ $=0.08)$ to become pregnant faster than cows calving twins.
Table 5. Association between gestation length category and milk production in Holstein cows

\begin{tabular}{|c|c|c|c|}
\hline Item (no. of cows) & $\begin{array}{l}\text { Milk production, } \\
\mathrm{kg} / \mathrm{d}\end{array}$ & SEM & $P$-value \\
\hline$\overline{\text { Gestation length }^{1}}$ & & & $<0.01$ \\
\hline AGL $(6,181)$ & 38.5 & 0.2 & - \\
\hline SGL $(762)$ & 36.6 & 0.3 & $<0.01$ \\
\hline LGL $(1,152)$ & 37.7 & 0.3 & $<0.01$ \\
\hline \multicolumn{4}{|l|}{ Parity } \\
\hline Primiparous $(3,242)$ & 34.3 & 0.3 & - \\
\hline Multiparous $(4,853)$ & 40.9 & 0.2 & $<0.01$ \\
\hline Gestation length $\times$ parity $^{2}$ & & & $<0.01$ \\
\hline Primiparous-AGL $(2,456)$ & 35.4 & 0.2 & - \\
\hline Primiparous-SGL (475) & 34.6 & 0.4 & 0.04 \\
\hline Primiparous-LGL (311) & 33.0 & 0.4 & $<0.01$ \\
\hline Multiparous-AGL $(3,725)$ & 41.6 & 0.2 & - \\
\hline Multiparous-SGL (287) & 38.6 & 0.4 & $<0.01$ \\
\hline Multiparous-LGL (841) & 42.4 & 0.3 & $<0.01$ \\
\hline \multicolumn{4}{|l|}{ Season of calving } \\
\hline Hot $(3,408)$ & 37.8 & 0.2 & - \\
\hline Cool $(4,687)$ & 37.3 & 0.2 & $<0.01$ \\
\hline Sex of calf & & & 0.20 \\
\hline Twin $(359)$ & 37.2 & 0.4 & - \\
\hline Male $(3,612)$ & 37.8 & 0.2 & 0.09 \\
\hline Female $(4,124)$ & 37.8 & 0.2 & 0.07 \\
\hline \multicolumn{4}{|l|}{ Farm } \\
\hline $1(1,841)$ & 37.7 & 0.3 & - \\
\hline $2(6,254)$ & 37.5 & 0.2 & 0.43 \\
\hline Gestation length $\times$ farm $^{2}$ & & & $<0.01$ \\
\hline Farm 1-AGL $(1,412)$ & 38.3 & 0.2 & - \\
\hline Farm 1-SGL (175) & 36.6 & 0.5 & $<0.01$ \\
\hline Farm 1-LGL (254) & 38.2 & 0.4 & 0.75 \\
\hline Farm 2-AGL $(4,769)$ & 38.6 & 0.2 & - \\
\hline Farm 2-SGL (587) & 36.7 & 0.3 & $<0.01$ \\
\hline Farm 2-LGL (898) & 37.2 & 0.3 & $<0.01$ \\
\hline
\end{tabular}

${ }^{1}$ Gestation length was categorized as average (AGL; population mean $\pm 1 \mathrm{SD}$; mean $=276 \mathrm{~d}$, range 270 to $282 \mathrm{~d}$ ), short (SGL; at least $1 \mathrm{SD}$ below the population mean; mean $=266 \mathrm{~d}$, range 256 to $269 \mathrm{~d}$ ), and long (LGL; $>1$ SD above the population mean; mean $=285 \mathrm{~d}$, range 283 to $296 \mathrm{~d})$.

${ }^{2}$ The $P$-values for pairwise comparisons were adjusted by the method of Tukey.

\section{Survival of Female Offspring}

Preweaning mortality was not associated with category of GL; however, heifers born from dams with SGL or LGL had greater $(P<0.01)$ postweaning mortality compared with heifers born from dams with AGL (Table 8$)$. As a result, a larger $(P<0.01)$ proportion of SGL and LGL heifers died by $300 \mathrm{~d}$ of age compared with heifers born from cows with AGL. Culling by 300 d of age did not differ with GL groups. The combined mortality and culling resulted in greater $(P<0.01)$ proportions of SGL and LGL heifers leaving the herd by $300 \mathrm{~d}$ of age compared with AGL heifers (Table 8). In fact, the daily rate of removal of heifers from the herd was 78 and $100 \%$ greater $(P<0.01)$ for SGL and LGL, respectively, than that of AGL (Table 9; Figure 4). Removal from the herd was also affected $(P<0.01)$ by season of birth and farm; heifers born during the 
cool season left the herd at a lesser rate than those born in the hot season.

\section{Reproductive Performance of Female Offspring}

The proportion of heifers receiving at least one AI was greater $(P<0.01)$ for AGL compared with SGL or LGL (Table 8). The mean age at first AI for inseminated heifers differed $(P<0.01)$ and SGL heifers were 2 and 5 d older than AGL and LGL heifers, respectively; however, when all heifers were considered in the analysis, then the median age at first AI differed $(P<0.05)$ by only $1 \mathrm{~d}$ between AGL and SGL, and tended $(P=0.07)$ to differ by $1 \mathrm{~d}$ between SGL and LGL. Pregnancy at first AI tended $(P=0.08)$ to be associated with GL category, and it was greater $(P<0.05)$ for heifers born from dams with SGL than for heifers born from dams with LGL. No statistical difference was observed for P/ AI at first AI between AGL and SGL or AGL and LGL heifers. Nevertheless, by $500 \mathrm{~d}$ of age, a greater $(P<$ 0.01) proportion of heifers born from AGL than LGL cows were pregnant and the difference observed for $\mathrm{P} /$ AI at first AI between SGL and LGL was no longer observed by $500 \mathrm{~d}$ of age (Table 8 ).

\section{DISCUSSION}

Parturition is triggered by the increase in fetal glucocorticoid concentrations because of maturation and activation of the fetal hypothalamic-pituitary-adrenal axis (Matthews and Challis, 1996), and several factors were associated with changes in length of gestation, including sex of the calf, parity of the cow, and season of calving. Cows carrying a male singleton had longer GL than cows carrying female calves. In addition, twin gestation of 2 male calves was longer than twin gestation with at least one female calf. It seems that final development of the hypothalamic-pituitary-adrenal axis may take longer in males, thereby resulting in longer GL. Hypoxemia is a potent stimulus to increase activity of the hypothalamic-pituitary-adrenal axis in the fetus (Matthews and Challis, 1996) and results in parturition. Primiparous cows are smaller than multiparous cows with reduced space to accommodate the growing uterus and calf in the abdominal cavity at the end of gestation, which might create potential stress to the fetus and alter blood flow and oxygen availability, thereby stimulating activity of the hypothalamicpituitary-adrenal axis. This might explain the shorter GL typically observed in primiparous compared with multiparous cows. Cows calving during the hot season had $1.5 \mathrm{~d}$ shorter GL than cows calving during the cool season. It is well described that heat stress can induce earlier parturition, and providing evaporative cooling 
to late-gestation cows under heat stress mitigates this effect and extends gestation another 3 to $4 \mathrm{~d}$ compared with cows not receiving evaporative cooling (Tao and Dahl, 2013). It is possible that heat stress promotes maturation of the hypothalamic-pituitary-adrenal axis and cortisol release by the fetus, leading to parturition sooner compared with cows calving during the cool season, which explains the link between season of the year and the length of gestation observed in the current study and by others (Norman et al., 2009).

In general, cows with SGL suffered from greater incidence of stillbirths, twins, and morbidity than cows with AGL, and the increments in disease incidence in cows with SGL were more exacerbated in multiparous than in primiparous cows. On the other hand, compared with AGL, those with LGL had greater incidence of dystocia, stillbirth, RFM, and metritis in multiparous but not primiparous cows. Furthermore, the detrimental effect of LGL seemed to be less pronounced than that of SGL on health of dams. The greater morbidity in SGL compared with AGL cows resulted in higher risks of culling and death in the first $300 \mathrm{~d}$ of lactation. Stillbirths and RFM are important risk factors for metritis, and we expected that cows with SGL, which had a 2.5-fold greater incidence of stillbirths and 5-fold greater incidence of RFM, would have greater incidence of uterine diseases than AGL cows, approximately a 2 -fold increase.

Twins are a major risk factor for numerous other diseases, and a larger proportion of multiparous cows had twin calvings compared with primiparous cows. Because of that, further analyses were performed including only cows that had singleton calvings. Similar to the data including all cows, SGL dams calving singletons had greater incidence of dystocia, stillbirth, and morbidity compared with AGL or LGL dams calving singletons. The greater morbidity associated with SGL was more evident in multiparous than in primiparous cows. Also, even when only cows calving singletons were included in the analyses of data, morbidity was greater in multiparous LGL compared with multiparous AGL. Nevertheless, it is clear that twinning reduces GL, and a greater prevalence of twin calvings was present in cows with SGL, which will compromise subsequent health performance in that cohort of cows. The overall benefits observed for cow health and survival when GL was within $1 \mathrm{SD}$ from the mean were extended to production and reproduction. Furthermore, female offspring born from dams with GL between 270 and $282 \mathrm{~d}$ had improved survival, and a larger proportion of those heifers received AI and became pregnant by 500 d of age compared with heifers from dams with SGL or LGL.

Nogalski and Piwczyński (2012) and Hansen et al. (2004) established an association between short GL and incidence of stillbirths, and cows with GL between 275 and $280 \mathrm{~d}$ had the greatest proportion of unassisted calving and the lowest incidence of stillbirth calves compared with cows with GL $<275$ d. In addition, Norman et al. (2011) reported greater incidence of

Table 7. Cox's regression model for time to pregnancy up to 300 DIM in Holstein cows

\begin{tabular}{|c|c|c|c|c|}
\hline \multirow[b]{2}{*}{ Item (cows, no.) } & \multicolumn{2}{|c|}{ Days to pregnancy } & \multirow[b]{2}{*}{$\operatorname{AHR}^{1}(95 \% \mathrm{CI})$} & \multirow[b]{2}{*}{$P$-value } \\
\hline & Median $(95 \%$ CI $)$ & $\mathrm{LSM} \pm \mathrm{SEM}$ & & \\
\hline \multirow{2}{*}{\multicolumn{4}{|c|}{ Gestation length $^{2} \times$ parity }} & 0.03 \\
\hline & \multicolumn{4}{|c|}{ Primiparous } \\
\hline $\operatorname{AGL}(2,456)$ & 95 (91 to 99$)$ & $122.1 \pm 1.5$ & Referent & - \\
\hline SGL (475) & $96(85$ to 102$)$ & $121.0 \pm 3.6$ & $0.98(0.88$ to 1.10$)$ & 0.73 \\
\hline LGL (311) & $99(93$ to 111$)$ & $124.8 \pm 4.4$ & $0.95(0.83$ to 1.09$)$ & 0.46 \\
\hline \multicolumn{5}{|l|}{ Multiparous } \\
\hline AGL $(3,725)$ & 104 (101 to 108$)$ & $132.9 \pm 1.4$ & Referent & - \\
\hline SGL (287) & $110(94$ to 124$)$ & $134.6 \pm 5.2$ & $0.93(0.80$ to 1.09$)$ & 0.37 \\
\hline LGL (841) & 116 (109 to 124$)$ & $142.2 \pm 3.1$ & $0.89(0.81$ to 0.97$)$ & 0.01 \\
\hline \multicolumn{5}{|l|}{ Season of calving } \\
\hline Hot & $99(97$ to 102$)$ & $124.2 \pm 1.3$ & Referent & - \\
\hline Cool & $103(101$ to 107$)$ & $133.7 \pm 1.3$ & $0.89(0.85$ to 0.94$)$ & $<0.01$ \\
\hline \multicolumn{4}{|l|}{ Sex of calf } & 0.10 \\
\hline Twin & 116 (107 to 129$)$ & $140.4 \pm 4.8$ & Referent & - \\
\hline Male & 103 (101 to 106$)$ & $130.8 \pm 1.3$ & 1.08 (0.95 to 1.23$)$ & 0.25 \\
\hline Female & $98(95$ to 101$)$ & $126.6 \pm 1.4$ & $1.13(0.99$ to 1.29$)$ & 0.08 \\
\hline \multicolumn{5}{|c|}{$\begin{array}{l}\text { }{ }^{1} \text { Adjusted hazard ratio of the hazard rates from the Cox's regression between a level of the predictor compare } \\
\text { with the reference level for the same predictor. A value }<1 \text { indicates a reduced rate of the event, whereas } \\
\text { value }>1 \text { indicates an increase in the rate of the event. }\end{array}$} \\
\hline \multicolumn{5}{|c|}{$\begin{array}{l}{ }^{2} \text { Gestation length was categorized as average (AGL; population mean } \pm 1 \mathrm{SD} \text {; mean }=276 \mathrm{~d} \text {, range } 270 \text { to } 28 \\
\mathrm{~d} \text { ), short (SGL; at least } 1 \mathrm{SD} \text { below the population mean; mean }=266 \mathrm{~d} \text {, range } 256 \text { to } 269 \mathrm{~d} \text { ), and long (LGL } \\
>1 \text { SD above the population mean; mean }=285 \mathrm{~d} \text {, range } 283 \text { to } 296 \mathrm{~d} \text { ). }\end{array}$} \\
\hline
\end{tabular}



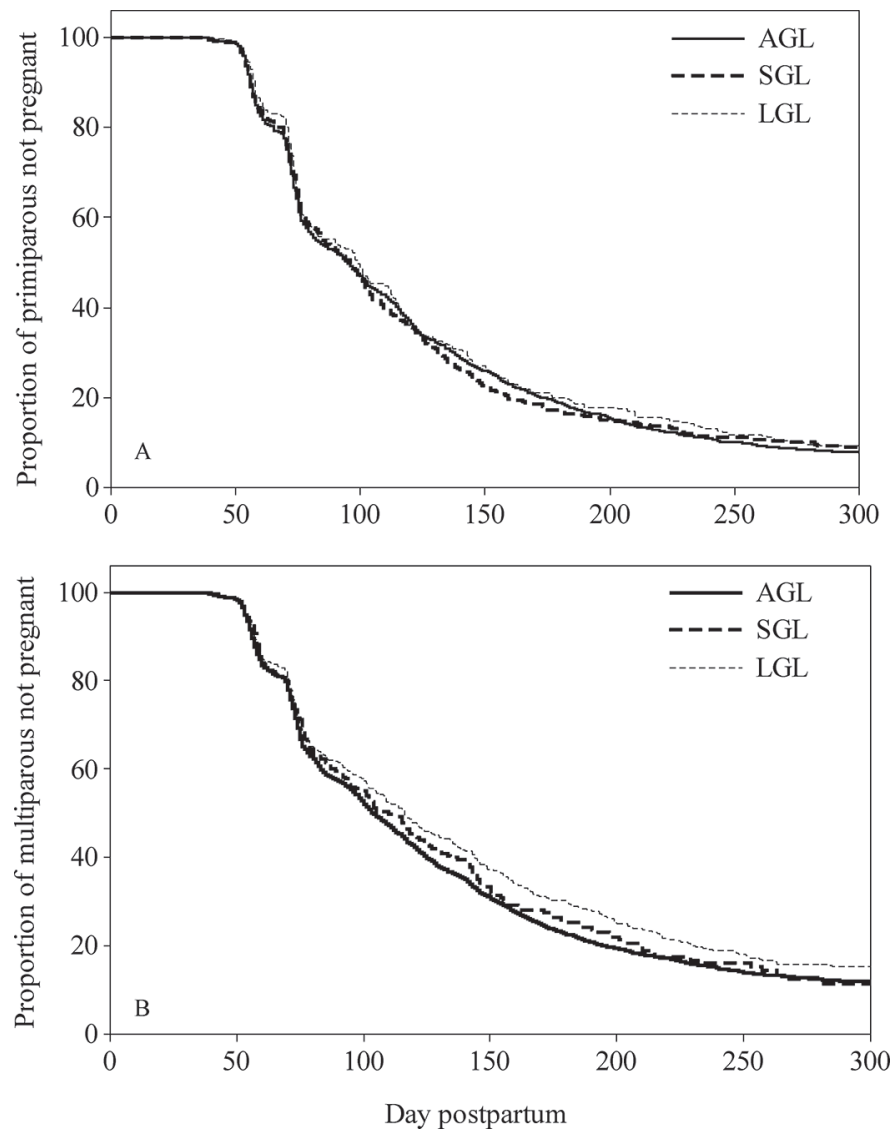

Figure 3. Survival curves for days postpartum to pregnancy in primiparous (A) and multiparous (B) Holstein cows up to 300 DIM according to gestation length category. Gestation length was categorized as average (AGL; population mean $\pm 1 \mathrm{SD}$; mean $=276 \mathrm{~d}$, range 270 to $282 \mathrm{~d} ; \mathrm{n}=6,181$ ), short (SGL; at least 1 SD below the population mean; mean $=266 \mathrm{~d}$, range 256 to $269 \mathrm{~d}$; $\mathrm{n}=762$ ), and long (LGL; $>1 \mathrm{SD}$ above the population mean; mean $=285 \mathrm{~d}$, range 283 to 296 $\mathrm{d} ; \mathrm{n}=1,152)$.

stillbirths in cows with GL $<274 \mathrm{~d}$ than in those with GL $>274$ d. Markusfeld (1984) concluded that short GL resulted in increased risk of RFM. Therefore, there is overwhelming evidence that GL shorter than 270 to $274 \mathrm{~d}$ is associated with impaired postpartum health in dams, and that the negative effects are extended to the offspring by reduced perinatal survival.

Long GL has also been associated with detrimental effects on health performance of dams and compromised perinatal survival of offspring (Hansen et al., 2004; Nogalski and Piwczyński, 2012). Moreover, Markusfeld (1984) concluded that cows with long GL had greater incidence of metritis. It is interesting to note that the negative associations between long GL and health in the current study were only observed in multiparous cows. Because a larger proportion of LGL multiparous cows had twin calvings compared with AGL multiparous, it was important to evaluate the data including only cows with singleton calvings. Even when only multiparous cows carrying singletons were evaluated, morbidity was greater for cows with LGL than those with AGL. These results reinforce those of others and the previous observation that cows with GL within 1 SD of the mean had improved health performance over those with either SGL or LGL.

The control of timing of calving is complex and involves fetal-maternal interactions (Matthews et al., 1995), but it is clear that timely onset of calving is critical for perinatal outcomes in cattle. It is unknown what exactly made cows with SGL calve earlier, particularly the 765 SGL cows carrying singletons, but fetal stress such as hypoxia and hypoglycemia may result in premature parturition because of accelerated maturation of the hypothalamic-pituitary-adrenal axis endocrine pathway (McMillen et al., 1995). Early parturition usually results in immature development of the lungs in the offspring, which can result in inadequate breathing, acidosis, and hypoxia, which might explain the increased incidence of stillbirths. Upon parturition, the dam's immune system immediately promotes an immune response against the remnants of fetal tissues and, in dairy cattle, RFM is thought to arise from failure of this mechanism of rejection of fetal tissues by the dam's immune system. As gestation progresses, major histocompatibility complex class I antigens are expressed on the placenta, which is thought to facilitate recognition and rejection of fetal placental tissues by the maternal immune system (Davies et al., 2004). The greater risk of RFM in dams with SGL may occur because the maternal immune system is less capable of rejecting the fetal components of the placenta. Detachment of the placenta requires degradation of collagen and proteolysis, which are carried out by maternal immune cells (Gross et al., 1985). Likely, cows with SGL lack the proper signals to activate the innate immune system required to eliminate the placenta, and the combination of lesser immune response and presence of remnant dead tissues likely explains the greater incidence of metritis than that in cows with AGL.

It was clear that deviations from the AGL resulted in marked increases in the rate of morbidity, and most diseases occurred in the first 3 wk of lactation. In fact, the high incidence of RFM and metritis in SGL cows meant that almost half of them were diagnosed with clinical disease by 8 DIM. In dairy cattle, approximately $45 \%$ of postpartum cows are diagnosed with at least one clinical disease in the first $60 \mathrm{~d}$ of lactation, and $75 \%$ of the first diagnoses of diseases in a lactation occur in the first $3 \mathrm{wk}$ postpartum (Ribeiro et al., 2016). Given the greater morbidity in cows with SGL than AGL or LGL, it is not surprising that the rate of removal from the herd by 300 DIM was markedly faster in this group 
Table 8. Survival and reproduction of Holstein heifers born alive according to gestation length

\begin{tabular}{|c|c|c|c|c|}
\hline \multirow[b]{2}{*}{ Item } & \multicolumn{3}{|c|}{ Gestation length category $^{1}$} & \multirow[b]{2}{*}{$P$-value } \\
\hline & AGL & SGL & LGL & \\
\hline Heifers, no. & 2,887 & 341 & 407 & - \\
\hline \multicolumn{5}{|l|}{ Death, \% } \\
\hline Preweaning & 1.7 & 3.3 & 3.8 & 0.28 \\
\hline Postweaning & $3.2^{\mathrm{b}, \mathrm{B}}$ & $6.6^{\mathrm{a}}$ & $5.4^{\mathrm{A}}$ & $<0.01$ \\
\hline By $300 \mathrm{~d}$ of age & $5.0^{\mathrm{b}}$ & $10.0^{\mathrm{a}}$ & $9.5^{\mathrm{a}}$ & $<0.01$ \\
\hline Culled by $300 \mathrm{~d}$ of age, $\%$ & 4.0 & 2.7 & 4.4 & 0.70 \\
\hline Left herd by $300 \mathrm{~d}$ of age, $\%$ & $10.8^{\mathrm{b}}$ & $13.6^{\mathrm{ab}}$ & $17.2^{\mathrm{a}}$ & 0.02 \\
\hline Inseminated, $\%$ & $85.3^{\mathrm{a}}$ & $84.2^{\mathrm{a}}$ & $76.2^{\mathrm{b}}$ & $<0.01$ \\
\hline \multicolumn{5}{|l|}{ Age at first AI, d } \\
\hline Heifers with AI, LSM \pm SEM & $413.1 \pm 0.8^{\mathrm{b}}$ & $415.1 \pm 1.1^{\mathrm{a}}$ & $409.5 \pm 1.0^{\mathrm{c}}$ & $<0.01$ \\
\hline All heifers, median $(95 \% \mathrm{CI})$ & $410^{\mathrm{b}}(410-410)$ & $411^{\mathrm{aA}}(410-412)$ & $410^{\mathrm{B}}(409-412)$ & 0.10 \\
\hline Pregnant at first AI, $\%$ & 64.5 & $69.3^{\mathrm{A}}$ & $60.3^{\mathrm{B}}$ & 0.08 \\
\hline Pregnant by $500 \mathrm{~d}$ of age, $\%$ & 77.8 & 74.7 & 69.3 & 0.27 \\
\hline
\end{tabular}

of cows than those with AGL. It is interesting to note that mortality increased only in multiparous cows with LGL, not in primiparous or multiparous cows with SGL, although SGL cows had greater morbidity than cows with AGL regardless of parity. Cows with LGL usually deliver larger and heavier calves, and dystocia is a very important risk factor for mortality in dairy cows. Perhaps multiparous cows with LGL had more calving trauma from larger calves that resulted in greater mortality. Dystocia was greater in multiparous cows with SGL than in those with AGL. One could

Table 9. Cox's regression model for time to removal from the herd up to $300 \mathrm{~d}$ of age in Holstein heifers

\begin{tabular}{lccc}
\hline Item (no. of heifers) & AHR $^{1}$ & $95 \%$ CI & $P$-value \\
\hline Gestation length $^{2}$ & & & $<0.01$ \\
AGL (2,887) & Referent & - & - \\
SGL (341) & 1.78 & 1.26 to 2.52 & $<0.01$ \\
LGL (407) & 2.00 & 1.45 to 2.76 & $<0.01$ \\
Parity of dam & & & \\
Primiparous (1,412) & Referent & - & - \\
Multiparous (2,223) & 0.86 & 0.67 to 1.11 & 0.23 \\
Season of birth & Referent & & \\
Hot (1,491) & 0.69 & 0.54 to 0.89 & $<0.01$ \\
Cool (2,144) & Referent & & \\
Farm & 0.62 & 0.48 to 0.80 & $<0.01$ \\
1 (831) & &
\end{tabular}

${ }^{1}$ Adjusted hazard ratio of the hazard rates from the Cox's regression between a level of the predictor compared with the reference level for the same predictor. A value $<1$ indicates a reduced rate of the event, whereas a value $>1$ indicates an increase in the rate of the event.

${ }^{2}$ Gestation length was categorized as average (AGL; population mean $\pm 1 \mathrm{SD}$; mean $=276 \mathrm{~d}$, range 270 to $282 \mathrm{~d}$ ), short (SGL; at least $1 \mathrm{SD}$ below the population mean; mean $=266 \mathrm{~d}$, range 256 to $269 \mathrm{~d}$ ), and long (LGL; >1 SD above the population mean; mean $=285 \mathrm{~d}$, range 283 to 296 d). argue that the high prevalence of twinning in multiparous cows with SGL likely caused the greater risk of dystocia; however, the greater incidence of dystocia in SGL than AGL multiparous cows was also observed when only dams carrying singletons were included in the statistical analysis. The reduced calf viability in cows with SGL might impair normal delivery, resulting in increased need for assistance during calving. Eventually, the augmented perinatal and health problems in cows with SGL resulted in greater incidence of culling in that lactation compared with cows with AGL.

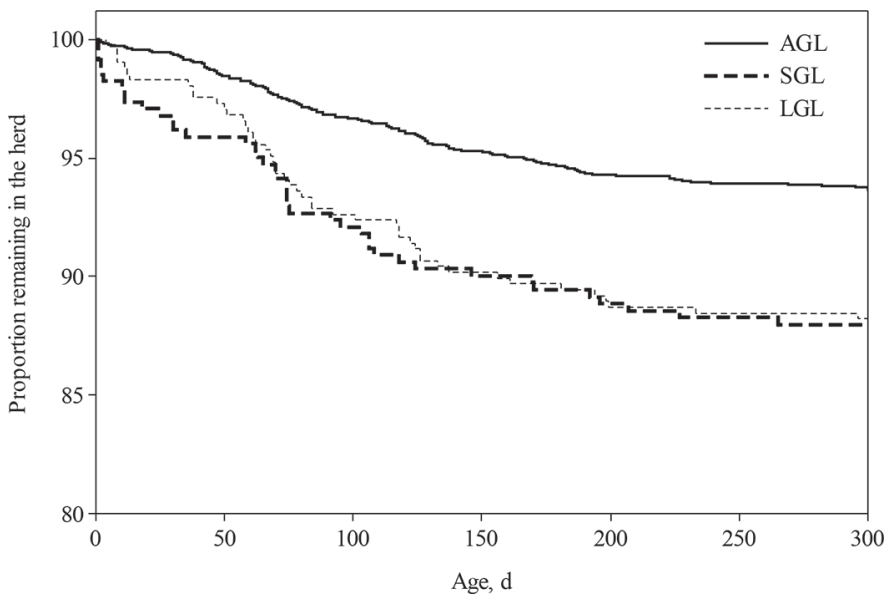

Figure 4. Survival curves for age at removal from the herd up to $300 \mathrm{~d}$ of age in heifers according to gestation length category of their dams. Gestation length was categorized as average (AGL; population mean $\pm 1 \mathrm{SD}$; mean $=276 \mathrm{~d}$, range 270 to $282 \mathrm{~d} ; \mathrm{n}=2,887$ ), short (SGL; at least $1 \mathrm{SD}$ below the population mean; mean $=266 \mathrm{~d}$, range 256 to $269 \mathrm{~d} ; \mathrm{n}=341$ ), and long (LGL; $>1 \mathrm{SD}$ above the population mean; mean $=285 \mathrm{~d}$, range 283 to $296 \mathrm{~d} ; \mathrm{n}=407$ ). 
Norman et al. (2011) concluded that milk production of multiparous cows increased as GL increased. The same authors demonstrated that milk fat and true protein were linearly and positively associated with GL; that is, as GL increased, so did yields of fat and true protein. Jenkins et al. (2016) evaluated productive performance of cows in seasonally calving dairy herds and found that GL category was a predictor for yields of milk, fat, and protein. Cows with GL within the shortest $5 \%$ and the longest $5 \%$ of the study population were less productive with lower yields of milk and milk components compared with cows with intermediate duration of gestation. The current study showed that cows with SGL or LGL produced less milk than herdmates with AGL; however, the effect of GL on production depended on the parity of cows. In multiparous cows, those with SGL had less milk yield, whereas those with LGL had greater milk yield than herdmates with AGL. For primiparous cows, those with SGL or LGL produced less milk than those with AGL. A short duration of gestation in multiparous cows might have implications for the length of the dry period and exposure of the transition group to dietary manipulations. Furthermore, during the last 2 wk of gestation, plasma concentrations of estrone and estrone sulfate increase concurrent with a sharp decrease in concentrations of progesterone (Thatcher et al., 1980). Eley et al. (1981) showed that concentrations of prolactin were positively associated with concentrations of estrone and negatively associated with those of progesterone; therefore, the shift in steroidogenesis influences prolactin production, which is important for galactopoiesis. Cows with abnormal GL likely had these shifts in steroidogenesis occurring in different times of gestation and relative to parturition, which could have affected the peak of prolactin at the onset of lactation, thereby influencing subsequent galactopoiesis. Also, the increased incidence of diseases, many of which are known to reduce milk yield, in association with the short dry period and less exposure to transition group management might explain the reduction in milk yield in multiparous cows with duration of gestation $<270 \mathrm{~d}$. Because of the observational nature of this study, further research is needed to better understand the implications of GL on subsequent production in dairy cows.

Gestation length category was not associated with impairment of reproductive performance at first AI in dams. That was unexpected because multiparous cows with SGL or LGL and primiparous cows with SGL had greater morbidity than cows with AGL, being particularly affected by diseases that harm the reproductive tract, and those diseases are known to impair reproduction in dairy cows (Ribeiro et al., 2016). Cows with SGL and LGL left the herd earlier than cows with
AGL, and cows removed early in lactation are normally those with health disorders and less prompt to adequate reproduction. It is possible that early removal from the herd in SGL and LGL groups might have led to an underestimation of the effect of SGL and LGL on P/ $\mathrm{AI}$ and pregnancy loss at first AI because those animals did not have the chance to participate in the reproductive program and were not included in the analysis of pregnancy at first AI. The smaller number of cows with SGL and multiparous cows with LGL that received at least one AI compared with other groups supports this hypothesis. Nonetheless, the proportion of cows pregnant by the end of the 300-d observation period showed that SGL compromised reproduction in dairy cows. Although no difference was observed between primiparous cows with AGL and LGL, a smaller proportion of multiparous cows with LGL became pregnant by 300 DIM compared with multiparous AGL cows. In fact, the rate of pregnancy was $11 \%$ less in multiparous cows with LGL compared with multiparous cows with AGL. It seems that the harm of abnormal GL on reproduction of dairy cows is not time-specific and carries over the entire lactation. In agreement with our findings, Norman et al. (2011) showed that cows with either short or long GL had greater days open compared with cows with average GL, thereby suggesting impaired reproductive performance.

Associations among GL and health, survival, and reproduction were also established for female offspring. Heifer mortality was greater in SGL or LGL than in AGL. This negative effect was observed during the postweaning period, which resulted in larger proportions of SGL and LGL calves dead by $300 \mathrm{~d}$ of age compared with calves born from AGL dams. In fact, the rate of removal of heifers from the herd was faster when the duration of gestation of the dams deviated from AGL.

As parturition approaches, the fetal lungs undergo biochemical, physiologic, and morphologic changes to adapt to postnatal life. One of those adaptations is the increase in production of pulmonary surfactants essential to prevent alveolar collapse and to maintain bronchiolar patency during respiration in extra-uterine life (Rooney, 1985). Calves born before $270 \mathrm{~d}$ of gestation are at a greater risk of developing respiratory distress syndrome than calves born after $270 \mathrm{~d}$ of gestation (Eigenmann et al., 1984). Calves born from cows with SGL may have had greater mortality because of the susceptibility to pulmonary disorders as their lungs were immature. Similar processes could have occurred in the digestive and immune systems, which could have affected colostrum absorption and the ability to fight gastrointestinal infections common to the preweaning and early postweaning periods. Premature calves have 
been shown to have an immature small intestine compared with full-term calves (Bittrich et al., 2004). Thus, SGL calves may have had more respiratory and digestive disorders, predisposing them to greater mortality than calves with AGL (Virtala et al., 1996). Nogalski and Piwczyński (2012) reported a linear relationship between GL and calf birth weight; therefore, LGL calves were probably heavier at birth. Johanson and Berger (2003) showed a linear and positive relationship between calf birth weight and perinatal mortality; that is, longer gestation resulted in heavier calves that had increased mortality. Larger, heavier calves at birth are associated with more calving difficulty, and the stress suffered during parturition may compromise transfer of passive immunity and increase susceptibility to development of diseases and, consequently, mortality. Among all cows and cows with singleton gestations, dystocia was greater in multiparous cows with LGL compared with those with AGL. Therefore, difficult calving might have influenced subsequent survival of offspring from cows with LGL.

Reproductive performance of female offspring was associated with GL. Of the 3,635 heifers born alive, a larger portion of SGL and LGL never received an AI by $500 \mathrm{~d}$ of age, compared with AGL. Approximately $64 \%$ of the 426 noninseminated heifers had left the herd by $300 \mathrm{~d}$ of age either because of death or culling. The remaining $36 \%$ were not inseminated by $500 \mathrm{~d}$ of age because they left the herd between 300 and $500 \mathrm{~d}$ of age, were not observed in estrus, or were moved to a group of heifers with natural service. Of the heifers that received at least one $\mathrm{AI}$, the $\mathrm{P} / \mathrm{AI}$ at first insemination was lowest for those from dams with LGL, which eventually resulted in a smaller proportion of LGL pregnant by $500 \mathrm{~d}$ of age compared with SGL. Unfortunately, incidence of diseases in calves was not available for this study, but the greater mortality suggests increased morbidity in SGL and LGL, and calves with diseases in early life have delayed first pregnancy (WaltnerToews et al., 1986). In addition, morbidity is associated with less BW gain, which can influence time to reach puberty and subsequent reproduction. It is interesting that heifers born from SGL dams that received AI had reproductive performance that did not differ from heifers born from AGL dams. Perhaps the greater rate of removal from the herd in SGL and LGL compared with AGL heifers attenuated the negative consequences to reproduction because those most affected either died or were culled prematurely.

The present data reinforce the relevance of GL to performance of dairy cows and their offspring and raise questions about the possibility and viability of using sires to select for a more homogeneous GL. Further re- search is needed to establish whether selection for short GL can be used without detrimental effects on health, productive, and reproductive performance of cows and their offspring. Furthermore, as GL has a high service sire heritability (Hansen et al., 2004), genetic selection of this trait may be of interest in the near future. In addition, the use of sires with long GL for cows with history of short GL and sires with short GL with cows with history of long GL may be a strategy to achieve an optimum GL that could result in better performance of dams and offspring.

\section{CONCLUSIONS}

Abnormal GL, based on deviations of at least $1 \mathrm{SD}$ from the population mean or $276( \pm 6)$ d, was associated with impaired health, productive, and reproductive performance in Holstein cows. Associations of short or long GL with impaired health and performance depended, in part, upon parity of cows. Primiparous and multiparous cows with SGL had greater incidence of disorders related to the reproductive tract during the postpartum period than cows with AGL, which resulted in more morbidity in the first 90 DIM and culling by 300 DIM, and they had a faster rate of removal from the herd. To a lesser extent, multiparous cows with LGL were more affected by disorders that influence the reproductive tract and suffered from more morbidity in the first 90 DIM and mortality by 300 DIM than cows with AGL; however, the same negative association was not observed for primiparous cows with LGL. Primiparous cows with SGL or LGL produced less milk than primiparous cows with AGL. Similarly, multiparous cows with SGL produced less milk than multiparous cows with AGL; however, multiparous cows with LGL produced more milk than multiparous cows with AGL. A smaller proportion of SGL cows received at least one AI and became pregnant by 300 DIM, which was also observed in multiparous cows with LGL. Short GL resulted in greater perinatal mortality than AGL. Furthermore, the rate of removal from the herd of liveborn heifers increased 1.78- and 2.0-fold in SGL and LGL, respectively, compared with heifers born from dams with AGL. Offspring from dams with GL that deviated from AGL had greater postweaning mortality. The greater heifer loss resulted in smaller proportions of heifers from dams with SGL and LGL receiving at least one AI compared with heifers from dams with AGL. Collectively, these results indicate that deviations $>6 \mathrm{~d}$ from the mean GL of $276 \mathrm{~d}$ in Holstein cows are associated with depressed dam health, production, and reproduction. The negative effects of either short or long GL were also observed in the female calves born 
alive. Offspring from dams with AGL survived longer and had improved reproductive performance compared with those from cows with short or long GL.

\section{ACKNOWLEDGMENTS}

The authors thank the owners and staff of River Ranch and John de Jong dairies (Hanford, CA) for making data available for this study.

\section{REFERENCES}

Bittrich, S., C. Philipona, H. M. Hammon, V. Romé, P. Guilloteau, and J. W. Blum. 2004. Preterm as compared with full-term neonatal calves are characterized by morphological and functional immaturity of the small intestine. J. Dairy Sci. 87:1786-1795.

Brusveen, D. J., A. P. Cunha, C. D. Silva, P. M. Cunha, R. A. Sterry, E. P. B. Silva, J. N. Guenther, and M. C. Wiltbank. 2008. Altering the time of the second gonadotropin-releasing hormone injection and artificial insemination (AI) during Ovsynch affects pregnancies per AI in lactating dairy cows. J. Dairy Sci. 91:1044-1052.

Davies, C. J., J. R. Hill, J. L. Edwards, F. N. Schrick, P. J. Fisher, J. A. Eldridge, and D. H. Schlafer. 2004. Major histocompatibility antigen expression on the bovine placenta: its relationship to abnormal pregnancies and retained placenta. Anim. Reprod. Sci. 82-83:267-280.

DeFries, J. C., R. W. Touchberry, and R. L. Hays. 1959. Heritability of the length of the gestation period in dairy cattle. J. Dairy Sci. 42:598-606.

DuBois, P. R., and D. J. Williams. 1980. Increased incidence of retained placenta associated with heat stress in dairy cows. Theriogenology 13:115-121.

Echternkamp, S. E., and K. E. Gregory. 1999. Effects of twinning on gestation length, retained placenta, and dystocia. J. Anim. Sci. $77: 39-47$.

Eigenmann, U. J., H. A. Schoon, D. Jahn, and E. Grunert. 1984. Neonatal respiratory distress syndrome in the calf. Vet. Rec. 114:141-144.

Eley, D. S., W. W. Thatcher, H. H. Head, R. J. Collier, and J. Wilcox. 1981. Periparturient endocrine changes of conceptus and maternal units in Jersey cows bred for milk yield. J. Dairy Sci. 64:296-311.

Gross, T. S., W. F. Williams, J. E. Manspeaker, and E. Russek. 1985. In vitro proteolytic activity of the late pregnant and peripartum bovine placenta. J. Anim. Sci. 61(Suppl. 1):391-392.

Hansen, M., M. S. Lund, J. Pedersen, and L. G. Christensen. 2004. Gestation length in Danish Holsteins has weak genetic association with stillbirth, calving difficulty, and calf size. Livest. Prod. Sci. 91:23-33.

Jamrozik, J., J. Fatehi, G. J. Kistemaker, and L. R. Schaeffer. 2005. Estimates of genetic parameters for Canadian Holstein female reproduction traits. J. Dairy Sci. 88:2199-2208.

Jenkins, G. M., P. Amer, K. Stachowicz, and S. Meier. 2016. Phenotypic associations between gestation length and production, fertility, survival, and calf traits. J. Dairy Sci. 99:418-426.
Johanson, J. M., and P. J. Berger. 2003. Birth weight as a predictor of calving ease and perinatal mortality in Holstein cattle. J. Dairy Sci. 86:3745-3755.

LIC. 2016. Short gestation length. Livestock Improvement Corporation. Accessed May 2016. http://www.lic.co.nz/lic_Premier_ Sires_Teams.cfm.

Markusfeld, O. 1984. Factors responsible for post parturient metritis in dairy cattle. Vet. Rec. 114:539-542.

Matthews, S. G., and J. R. G. Challis. 1996. Regulation of the hypothalamo-pituitary-adrenocortical axis in fetal sheep. Trends Endocrinol. Metab. 7:239-246.

Matthews, S. G., F. Lu, K. Yang, and J. R. G. Challis. 1995. Hypothalamic pituitary adrenal function in the sheep fetus. Reprod. Fertil. Dev. 7:509-516.

McClintock, S., K. Beard, A. Gilmour, and M. Goddard. 2003. Relationship between calving traits in heifers and mature cows in Australia. Interbull Bull. 31:102-106.

McMillen, I. C., I. D. Phillips, J. T. Ross, J. S. Robinson, and J. A. Owens. 1995. Chronic stress - The key to parturition? Reprod. Fertil. Dev. 7:499-507.

Nogalski, Z., and D. Piwczyński. 2012. Association of length of pregnancy with other reproductive traits in dairy cattle. Asian-australas. J. Anim. Sci. 25:22-27.

Norman, H. D., J. R. Wright, M. T. Kuhn, S. M. Hubbard, J. B. Cole, and P. M. VanRaden. 2009. Genetic and environmental factors that affect gestation length in dairy cattle. J. Dairy Sci. 92:22592269.

Norman, H. D., J. R. Wright, and R. H. Miller. 2011. Potential consequences of selection to change gestation length on performance of Holstein cows. J. Dairy Sci. 94:1005-1010.

NRC. 2001. Nutrient Requirements of Dairy Cattle. 7th rev. ed. Natl. Acad. Sci. Washington, DC.

Olson, K. M., B. G. Cassell, A. J. McAllister, and S. P. Washburn. 2009. Dystocia, stillbirth, gestation length, and birth weight in Holstein, Jersey, and reciprocal crosses from a planned experiment. J. Dairy Sci. 92:6167-6175.

Ribeiro, E. S., G. Gomes, L. F. Greco, R. L. A. Cerri, A. Vieira-Neto, P. L. J. Monteiro Jr., F. S. Lima, R. S. Bisinotto, W. W. Thatcher, and J. E. P. Santos. 2016. Carryover impact of postpartum inflammatory diseases on developmental biology and fertility in lactating dairy cows. J. Dairy Sci. 99:2201-2220.

Rooney, S. A. 1985. The surfactant system and lung phospholipid biochemistry. Am. Rev. Respir. Dis. 131:439-460.

Silva, H. M., C. J. Wilcox, W. W. Thatcher, R. B. Becker, and D. Morse. 1992. Factors affecting days open, gestation length, and calving interval in Florida dairy cattle. J. Dairy Sci. 75:288-293.

Tao, S., and G. E. Dahl. 2013. Invited review: Heat stress effects during late gestation on dry cows and their calves. J. Dairy Sci. 96:4079-4093.

Thatcher, W. W., C. J. Wilcox, R. J. Collier, D. S. Eley, and H. H. Head. 1980. Bovine conceptus - maternal interactions during the pre- and postpartum periods. J. Dairy Sci. 63:1530-1540.

Virtala, A. M., G. D. Menchor, Y. T. Gröhn, and H. N. Erb. 1996. Morbidity from nonrespiratory diseases and mortality in dairy heifers during the first three months of life. J. Am. Vet. Med. Assoc. 208:2043-2046.

Waltner-Toews, D., S. W. Martin, and A. H. Meek. 1986. The effect of early calfhood health status on survivorship and age at first calving. Can. J. Vet. Res. 50:314-317. 